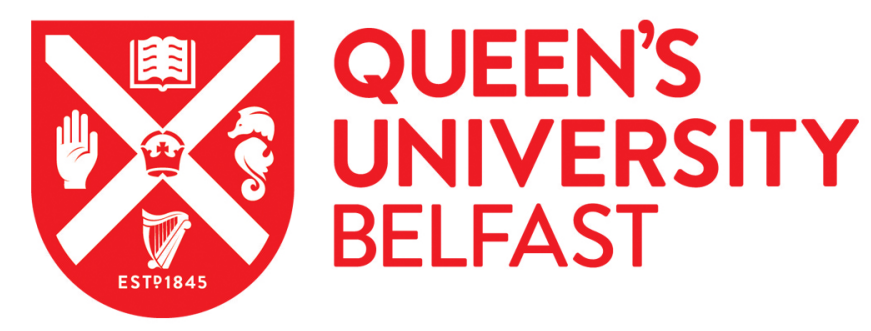

\title{
Fifteen-minute consultation: Symptoms and signs of meningococcal disease
}

Corr, M., Waterfield, T., \& Shields, M. (2019). Fifteen-minute consultation: Symptoms and signs of meningococcal disease. Archives of Disease in Childhood: Education and Practice Edition.

https://doi.org/10.1136/archdischild-2019-317722

Published in:

Archives of Disease in Childhood: Education and Practice Edition

Document Version:

Peer reviewed version

Queen's University Belfast - Research Portal:

Link to publication record in Queen's University Belfast Research Portal

Publisher rights

(C) 2019 Author(s) (or their employer(s)). No commercial re-use.

This work is made available online in accordance with the publisher's policies. Please refer to any applicable terms of use of the publisher.

\section{General rights}

Copyright for the publications made accessible via the Queen's University Belfast Research Portal is retained by the author(s) and / or other copyright owners and it is a condition of accessing these publications that users recognise and abide by the legal requirements associated with these rights.

Take down policy

The Research Portal is Queen's institutional repository that provides access to Queen's research output. Every effort has been made to ensure that content in the Research Portal does not infringe any person's rights, or applicable UK laws. If you discover content in the Research Portal that you believe breaches copyright or violates any law, please contact openaccess@qub.ac.uk. 


\section{Fifteen-minute consultation: symptoms and signs of meningococcal disease}

$\mathbf{1}^{\text {st }}$ Author: Dr Michael Corr

Queen's University Belfast

$2^{\text {nd }}$ Author: Dr Thomas Waterfield (Corresponding Author)

Queen's University Belfast

Northern Ireland

Email: twaterfield01@qub.ac.uk

Telephone: 07872990521

Co-Authors

$3^{\text {rd }}$ Author: Professor Michael Shields

Queen's University Belfast

Word count: 1593 


\section{Abstract}

Meningococcal disease remains a leading cause of meningitis, sepsis and death in children worldwide and in the UK. Successful vaccinations programmes in the UK have however, significantly reduced the burden of disease in children. Unfortunately, despite vaccination, a significant number of children are still diagnosed with invasive meningococcal disease each year.

As the prevalence of meningococcal disease falls, it is important that we maintain awareness of the symptoms and signs of meningococcal disease because the prompt recognition of this life-threatening infection improves outcomes.

In this article we discuss the pathology, epidemiology and recognition of invasive meningococcal disease in children. The aim is to maintain awareness of this rare but life-threatening infection.

\section{Introduction}

Many UK clinicians will recall regularly encountering invasive meningococcal disease prior to the introduction of the meningococcal C vaccination onto the UK vaccination schedule in 1999. All too often these children were extremely unwell, requiring prolonged admission and intensive care. These awful cases raised awareness of the disease and the importance of ongoing vigilance amongst healthcare professionals.

The successful introduction of the meningococcal C (1999) and B vaccinations (2015) onto UK vaccination schedule has led to a significant reduction in the number of cases of invasive meningococcal disease. This reduced burden of disease means that each year there have been fewer and fewer cases in the UK and some current UK paediatric trainees may have never encountered a child with invasive meningococcal disease.

This creates a diagnostic challenge for clinicians. How do we spot those children with meningococcal disease? Meningococcal disease is rare, but devastating so how do we maintain vigilance at a time when disease prevalence is at a record low and fewer pediatricians have experience of the disease? In this consultation we aim to review the symptoms and signs of meningococcal disease. 


\section{Invasive meningococcal disease}

Invasive meningococcal disease describes the process when the bacteria Neisseria meningitidis crosses from the respiratory mucosa and invades the host. Neisseria meningitidis is a gram-negative diplococcus that colonises the nasopharynx and oropharynx of humans (figure 1). In most people carriage is asymptomatic but in a minority the bacteria cross the mucosa and enters the blood. Once the N.meningitidis bacteria crosses from the nasopharynx to the blood, it multiples rapidly with resultant bacteraemia and an associated cytokine storm. This leads to increased host vascular permeability, organ dysfunction and disseminated intravascular coagulation. The bacteria may also cross the blood-brain barrier resulting in meningitis.

Figure 1: Gram stain showing N.meningitidis (Diplococci)

Creative Commons License: "This image is a work of the Centers for Disease Control and Prevention, part of the United States Department of Health and Human Services, taken or made as part of an employee's official duties. As a work of the U.S. federal government, the image is in the public domain." Dr. Brodsky. Modified by Mikael Häggström [Public domain]. https://commons.wikimedia.org/wiki/File:Neisseria meningitidis (cropped).png

\section{Neisseria meningitidis}

Neisseria meningitidis is an aerobic gram-negative diplococcus that has an outer polysaccharide capsule surrounding a three-layered envelope. The outer polysaccharide layer is the main virulence factor and the 13 known serogroups are defined by their polysaccharide layer [1]. Of the 13 known serogroups 6 are responsible for Human disease $(A, B, C, W, X, Y)$ [1]. The outer polysaccharide capsule aids in the avoidance of immune cells and has been shown to reduce phagocytosis by human dendritic cells [2]. It achieves this through a variety of mechanisms including molecular mimicry and the downregulation of complement [3-7]. Beneath the capsule there is the lipopolysaccharide layer. Following phagocytosis of the meningococcus by dendritic cells, this layer is exposed and stimulates cytokine release by the dendritic cell [2]. Lipopolysaccharides (also known as endotoxin) from Neisseria meningitidis have been shown to be extremely powerful stimulants of cytokine release including the release of TNF- $\alpha$ and Interleukins 1,6, and 8 from human macrophages [2]. This cytokine release is responsible for increased vascular permeability, organ dysfunction and disseminated 
intravascular coagulation (characterized by the presence of a purpuric rash) classical of meningococcal septicaemia [8]. An interim deterioration, and cardiovascular collapse, may occur following initial treatment with antibiotics due to rapid endotoxin release from lysed Neisseria meningitidis (9).

The lipopolysaccharide layer also contains various membrane proteins including; porins (for ion exchange), adhesion molecules and pili to facilitate invasion of the host. Neisseria meningitidis can also avoid the host immune response by altering the antigens presented on its surface through a process of phase variation and through the transfer of extracellular DNA.

\section{Epidemiology}

Humans are the only natural host for Neisseria meningitidis. Benign carriage is common with around a quarter of young adults carrying the bacteria in their nasopharynx or oropharynx [10]. Carriage rates vary with age [10]. A meta-analysis of 89 studies from across the world published in 2010 in the Lancet showed that carriage is lowest in infancy (4.5\%) but then increases through childhood to a peak in late adolescence (27.7\% at 19 years) [10]. The rates of carriage then reduce again throughout adulthood [10].

In addition to social and geographical factors it would appear that seasonal variations affect meningococcal disease rates. Winter is associated with increased meningococcal disease in both Africa and in Europe [11]. The reasons for this are unclear. It has been hypothesised that in Africa the dry winters are associated with reduced humidity and increased ease of spread whereas in Europe winter is associated with an increased risk of mucosal injury from other infectious agents leading to increased opportunistic meningococcal infection [11]. 
In the UK serogroup C was traditionally responsible for the majority of invasive disease with 883 laboratory confirmed cases in England in the 1998/1999 surveillance year [12]. This fell significantly following the introduction of the conjugate meningococcal $C$ vaccine into the routine immunisation schedule in November 1999[12]. In 2017/2018 there were 29 laboratory confirmed cases of invasive meningococcal $\mathrm{C}$ infection in people aged 18 and younger in England [12].

Meningococcal B infection is now the leading cause of invasive meningococcal infection in the UK with 278 laboratory confirmed cases in people aged 18 and younger in England in the 2017 to 2018 [12]. Meningococcal $B$ infection rates have been falling since the introduction of the meningococcal $B$ vaccine into the UK vaccination schedule in 2015[12]. In recent years there has been an increase in serogroup $\mathrm{W}$ and $\mathrm{Y}$ infections in England with University wide ACWY vaccination programmes having little effect on serogroup W carriage [13].

The rates of meningococcal sepsis are summarised in figure 2 based on data published by Public Health England [12].

Figure 2: Meningococcal sepsis in England - Based on English public health data [12]

\section{Identifying symptoms and signs}

The current UK standard of care is the NICE guideline "Meningitis (bacterial) and meningococcal septicaemia in under 16s: recognition, diagnosis and management clinical guideline [CG102] [14]. In this detailed guidance there are 31 potential symptoms and signs of meningococcal infection. These are divided into common and non-specific signs, less common and non-specific signs and more specific signs

Table 1. Symptoms and signs of invasive meningococcal disease 


\section{What are the symptoms and signs of invasive meningococcal infection in children?}

Part of the clinical challenge in diagnosing meningococcal disease is the varied and often non-specific ways it can present. This is exemplified by studies suggesting that half of meningococcal disease is not recognised at initial presentation (15).

Symptoms described in the NICE guidance such as lethargy, irritability and poor feeding are likely to feature in any child who is unwell, whilst others such as coryzal symptoms, nausea and vomiting and abdominal pain could lead a clinician to consider other potential viral or bacterial infections rather than meningococcal disease. The vague nature of these symptoms means any clinician ought to consider the possibility of meningococcal disease when assessing any unwell child. It is also important to appreciate that many of these symptoms should also raise suspicion of possible early sepsis. Additional sepsis guidance is available from NICE "Sepsis recognition, diagnosis and early management" (16).

\section{What symptoms or signs suggest are most specific for invasive meningococcal disease?}

Although many features of invasive meningococcal disease are subtle and non-specific, there are some symptoms and signs that are more specific for the disease and if present warrant further investigation and immediate treatment as per national guidance (14). These symptoms are summarised in Table $\mathbf{2}$, and have been highlighted by NICE and epidemiological studies as symptoms suggesting the greatest risk of invasive meningococcal disease [14, 17-18].

Table 2: Highest risk signs of invasive meningococcal disease 


\section{How do clinical features vary in children of different ages?}

The features of invasive meningococcal disease vary significantly depending on the age of the child as outlined in Table 3. In young children and infants, the features of infection may be more subtle. This is especially true when considering symptoms and signs of meningism. In younger children and infants features of meningitis include irritability, poor feeding and a full or bulging fontanelle $[17,19,20]$.

A summary table of the differences between young infants and older children is outlined in Table 3.

Table 3: Symptoms reported dependant on age

\section{Summary}

Invasive meningococcal disease is becoming less frequent in the UK following the successful introduction of meningococcal vaccination into the childhood vaccination schedule. Unfortunately, despite vaccination programmes children are still being diagnosed with, and dying from invasive meningococcal disease. As cases become less frequent our experience of recognising the disease reduces. It is important that we all remain vigilant and, where possible, diagnose cases as early as possible.

Many of the features of meningococcal disease are non-specific and it is advisable to at least consider the possibility of meningococcal disease or sepsis in any unwell child. In children with high risk features such as those outlined in Table 2 the emphasis should be on initiating appropriate immediate treatment and investigation as per current NICE guidance (14). 


\section{Clinical Bottom Line}

- Meningococcal vaccination has been hugely successful and meningococcal disease is rare in the UK

- Children do, however, still die every year from meningococcal disease

- Early meningococcal disease is hard to recognise and well appearing children can subsequently deteriorate. Safety-netting at discharge is of paramount importance.

- Consider meningococcal disease in any unwell child but especially in those with high risk features.

- In cases of suspected meningococcal infection there should be careful monitoring of the child's cardiovascular status before and after antibiotic administration. 


\section{References}

1. Harrison OB, Claus H, Jiang Y, Bennett JS, Bratcher HB, Jolley KA, et al. Description and Nomenclature of <em>Neisseria meningitidis</em> Capsule Locus. Emerg Infect Dis J. 2013;19:566. doi:10.3201/eid1904.111799.

2. Unkmeir A, Kämmerer U, Stade A, Haller S, Kolb-mäurer A, Dietrich G, et al. Lipooligosaccharide and Polysaccharide Capsule : Virulence Factors of Neisseria meningitidis That Determine Meningococcal Interaction with Human Dendritic Cells Lipooligosaccharide and Polysaccharide Capsule : Virulence Factors of Neisseria meningitidis T. Infect Immun. 2002;70:2454-62. doi:10.1128/IAI.70.5.2454.

3. Tsai CM. Molecular mimicry of host structures by lipooligosaccharides of Neisseria meningitidis: characterization of sialylated and nonsialylated lacto-N-neotetraose (Galbeta1-4GlcNAcbeta13Galbeta1-4Glc) structures in lipooligosaccharides using monoclonal antibodies and specific lectins. Adv Exp Med Biol. 2001;491:525-42. http://www.ncbi.nlm.nih.gov/pubmed/14533820. Accessed 9 Jan 2018.

4. Moran AP, Prendergast MM, Appelmelk BJ. Molecular mimicry of host structures by bacterial lipopolysaccharides and its contribution to disease. FEMS Immunol Med Microbiol. 1996;16:105-15. http://www.ncbi.nlm.nih.gov/pubmed/8988391. Accessed 9 Jan 2018.

5. Mandrell RE, Apicella MA. Lipo-oligosaccharides (LOS) of mucosal pathogens: Molecular mimicry and host-modification of LOS. Immunobiology. 1993;187:382-402. doi:10.1016/S0171-2985(11)80352-9.

6. Moe GR, Granoff DM. Molecular Mimetics of Neisseria meningitidis Serogroup B Polysaccharide. Int Rev Immunol. 2001;20:201-20. doi:10.3109/08830180109043034.

7. Drogari-Apiranthitou M, Kuijper EJ, Dekker N, Dankert J. Complement activation and formation of the membrane attack complex on serogroup B Neisseria meningitidis in the presence or absence of serum bactericidal activity. Infect Immun. 2002;70:3752-8.

http://www.ncbi.nlm.nih.gov/pubmed/12065518. Accessed 9 Jan 2018.

8. Griffiss JM, Schneider H, Mandrell RE, Yamasaki R, Jarvis GA, Kim JJ, et al. Lipooligosaccharides: the principal glycolipids of the neisserial outer membrane. Rev Infect Dis. 10 Suppl 2:S287-95.

http://www.ncbi.nlm.nih.gov/pubmed/2460911. Accessed 9 Jan 2018.

9. Lepper PM, Held TK, Schneider EM, et al. Clinical implications of antibiotic-induced endotoxin release in septic shock. Intensive Care Med. 2002; 28(7): 824-33

10. Christensen H, May M, Bowen L, Hickman M, Trotter CL. Meningococcal carriage by age: a systematic review and meta-analysis. Lancet Infect Dis. 2010;10:853-61. doi:10.1016/S1473-3099(10)70251-6.

11. Palmgren H. Meningococcal disease and climate. Glob Health Action. 2009;2:1-8.

12. Meningococcal disease: guidance, data and analysis. Public Health Agency Available from www.gov.uk. Accessed 8 Jan 2018.

13. Oldfield NJ, Cayrou C, AlJannat MAKK, Al-Rubaiawi AAAA, Green LR, Dada S, et al. Rise in group W meningococcal carriage in university students, United Kingdom. Emerg Infect Dis. 2017;23:1009-11. doi:10.3201/eid2306.161768.

14. NICE Clinical Guidelines: CG102 Meningitis (bacterial) and meningococcal septicaemia in under 16s: recognition, diagnosis and management. 2010

15. Thompson MJ, Ninis N, Perera R, Mayon-White R, Phillips C, Bailey L, et al. Clinical recognition of meningococcal disease in children and adolescents. The lancet 2006;367(9508):397-403

16. Nice Clinical Guidelines: NG51: Sepsis recognition, diagnosis and early management. 2017

17. Ragunathan, L., Ramsay, M., Borrow, R., Guiver, M., Gray, S., \& Kaczmarski, E. B. (2000). Clinical features, laboratory findings and management of meningococcal meningitis in England and Wales: Report of a 1997 survey. Journal of Infection, 40(1), 74-79. https://doi.org/10.1053/jinf.1999.0595

18. Waterfield T, Dyer EM, Lyttle MD. Fifteen-minute consultation: the child with a non-blanching rash. Archives of Disease in Childhood - Education and Practice 2018;103:236-240.

19. Johansson Kostenniemi, U., Norman, D., Borgström, M., \& Silfverdal, S. A. (2015). The clinical presentation of acute bacterial meningitis varies with age, sex and duration of illness. Acta Paediatrica, International Journal of Paediatrics, 104(11), 1117-1124. https://doi.org/10.1111/apa.13149

20. Tracy A, Waterfield T. How to use clinical signs of meningitis. Archives of Disease in Childhood Education and Practice.Published Online First: 28 January 2019. doi: 10.1136/archdischild-2018315428 
TABLE 1: Symptoms and signs of invasive meningococcal disease

\begin{tabular}{|l|l|l|}
\hline Non-specific signs & Specific signs (Sepsis) & Specific signs (Meningitis) \\
\hline Abdominal Pain & Purpura & Headache \\
\hline Nausea \& Vomiting & Non-blanching Rash & Reduced GCS \\
\hline Diarrhoea & Reduced GCS & Neck Stiffness \\
\hline Lethargy & Myalgia & Photophobia \\
\hline Irritable & Cold Extremities & Seizure \\
\hline Coryzal Symptoms & Tachycardia & Neurological Deficit \\
\hline Fever & Ill Appearance & \\
\hline Tachypnoea & Pallor & \\
\hline Sore Throat & Shock & \\
\hline Refusing Food/drink & Leg Pain & \\
\hline
\end{tabular}

Table 2: Highest risk signs of invasive meningococcal disease

\section{CLINICAL FEATURE}

NON-BLANCHING RASH

NECK STIFFNESS

PHOTOPHOBIA

LEG PAIN

REDUCED GCS 
Table 3: Symptoms reported dependant on age

\begin{tabular}{|l|l|}
\hline Infants & Older Children \\
\hline Tachypnoea & Neck Stiffness \\
\hline Pallor & Headache \\
\hline Seizures & Photophobia \\
\hline Irritability & Nausea and vomiting \\
\hline Refusing Feed & Leg Pain \\
\hline Bulging Fontanelle & \\
\hline
\end{tabular}

